Printed in Great Britain

\title{
Evidence for the Presence of Fimbriae (Pili) on Vibrio Species
}

\author{
By JEAN M. TWEEDY*, R. W. A. PARK \\ The Department of Microbiology, The University, Reading \\ AND W. HODGKISS \\ Torry Research Station, Aberdeen
}

(Accepted for publication 29 September 1967)

\begin{abstract}
SUMMARY
Three strains of Vibrio were found to agglutinate both guinea-pig and human red cells. The vibrios differed in haemagglutination tests from fimbriated enterobacteria by showing only partial inhibition by mannose and by agglutinating guinea-pig and human red cells equally well. Electron microscopy of the vibrios revealed filamentous appendages which resembled the common fimbriae of Escherichia coli in having average diameters between 6 and $10 \mathrm{~m} \mu$ and in being more numerous on organisms from liquid media than from solid media. The fimbriae on vibrios also had some characteristics of $\mathrm{F}$ fimbriae of enterobacteria. In comparative studies fimbriae which resembled common fimbriae of $E$. coli were found on Pseudomonas multivorans and Aeromonas liquefaciens.
\end{abstract}

\section{INTRODUCTION}

Fimbriae are too narrow to be seen with the light microscope but they can be seen with the electron microscope. For many enterobacteria fimbriae can also be detected by a haemagglutination test, first used for the purpose by Duguid, Smith, Dempster \& Edmunds (1955). Although non-fibrial haemagglutination (i.e. haemagglutination by bacteria which is not due to fimbriae) sometimes occurs it differs from fimbrial haemagglutination by occurring only at low temperature, clumps of red cells breaking up as a result of elution of the bacteria as the temperature is raised to $40^{\circ}-50^{\circ}$ (Duguid, 1964). Also, non-fimbrial haemagglutination is not inhibited by mannose, unlike haemagglutination due to type $I$ and type 6 fimbriae and the adhesin of type 5 fimbriae (Duguid, I964; Duguid, Anderson \& Campbell, I966). Some cultural characters such as the formation of pellicles in broth by some enterobacteria (Duguid \& Gillies, 1957; Duguid, I959; Shedden, 1962) are associated with the presence of fimbriae.

During characterization tests of some vibrios it was noticed that pellicles were produced in nutrient broth by some strains but not by others, an observation which suggested that some vibrios might possess fimbriae. We therefore examined some of these vibrios for fimbriae by using the haemagglutination test and by electron microscopy. In this paper we report our findings. We have referred to as fimbriae any filamentous appendages other than flagella found on vibrios, but this does not imply that such

\footnotetext{
* Present address: Microbiology Department, Trinity College, Dublin 2.
} 
appendages had all the properties described for fimbriae of other organisms. We use the word 'fimbriae' (Duguid et al. 1955) rather than 'pili' (Brinton, 1959) because it has priority and because we accepted the other points (Duguid, I966) in favour of 'fimbriae'.

\section{METHODS}

Organisms. The vibrios studied were: Vibrio cholerae NCTC $802 \mathrm{I}$, Vibrio eltor NCTC 5395 and Vibrio sp. NCTC 4716 (hereafter called Vibrio 4716). Also included in the study were: Pseudomonas multivorans NCIB 969I (strain I04 of Stanier, Palleroni \& Doudoroff, 1966), Aeromonas liquefaciens NCMB 87 (strain L 417 of Kluyver; see Miles \& Miles, I95I), and Escherichia coli Microbiology Department, Reading University strain 16 A.

Media. Organisms were grown either on nutrient agar (blood agar base, Oxoid; $\mathrm{pH} \mathrm{7.5)}$ sloped in I oz. universal screw-cap bottles, or in tryptone water $(\%, w / v$, tryptone, Oxoid, $\mathrm{I} \cdot 0 ; \mathrm{NaCl}, 0.5$; in demineralized water; $\mathrm{pH} 7 \cdot 4$ ) in $\mathrm{IO} \mathrm{ml}$. amounts in $6 \times 5 / 8$ in. test-tubes. Organisms were subcultured to these media from stock cultures on nutrient agar slopes and were incubated for $24 \mathrm{hr}$ or $72 \mathrm{hr}$ at $20^{\circ}, 25^{\circ}$ or $37^{\circ}$.

Haemagglutination tests. Tile tests, using cells from human blood or guinea-pig blood and $2 \%$ (w/v) D-mannose, were performed as described by Cruickshank (1965). Cells separated by centrifugation from fresh citrated blood were washed twice in saline $(0.85 \%, \mathrm{w} / \mathrm{v}, \mathrm{NaCl}$ in demineralized water) and made up to a $3 \%(\mathrm{v} / \mathrm{v})$ suspension in saline. Organisms grown on solid media were harvested by adding $\mathrm{r} \cdot 0 \mathrm{ml}$. saline to each slope and gently emulsifying the growth. The resultant suspension of organisms was deposited by centrifugation; most of the supernatant fluid was poured off and the deposit of each culture then resuspended in the small amount of remaining fluid. Tryptone water cultures were centrifuged and most of the supernatant fluid then poured off. The organisms were resuspended in the small amount of remaining fluid. Each test was performed by adding reagents in the order shown in Table I to depressions in a tile previously chilled to $3-5^{\circ}$. The tile was then rocked gently for $5 \mathrm{~min}$. while it warmed to room temperature and was examined each minute. For studies to determine the effect of heat treatment on haemagglutinating ability, each strain was passed through 3 subcultures at intervals of $24 \mathrm{hr}$ in tryptone water. One tube of the final culture was centrifuged and the deposit heated in a boiling water bath for $30 \mathrm{~min}$. The deposit was cooled to room temperature by placing the tube in a water bath at $20^{\circ}$ and was then tested for haemagglutinin.

Table I. Amounts of reagents (in $\mathrm{ml}$.) added to depressions in chilled tiles in haemagglutination tests with 3 strains of Vibrio and I strain each of Escherichia coli, Pseudomonas multivorans and Aeromonas liquefaciens

\section{Reagent}

(1) $3 \%(\mathrm{v} / \mathrm{v})$ guinea-pig red-cell suspension

(2) $3 \%(v / v)$ human red-cell suspension

(3) $2 \%(w / v) ~ D-m a n n o s e *$

(4) Saline

(5) Dense bacillary suspension

\begin{tabular}{|c|c|c|c|c|c|}
\hline \multicolumn{6}{|c|}{ Depression number } \\
\hline I & 2 & 3 & 4 & 5 & 6 \\
\hline 0.02 & 0.02 & . & . & 0.02 & . \\
\hline . & . & 0.02 & 0.02 & . & 0.02 \\
\hline . & 0.02 & . & 0.02 & . & . \\
\hline 0.02 & . & 0.02 & . & 0.04 & 0.04 \\
\hline 0.02 & 0.02 & 0.02 & 0.02 & . & . \\
\hline
\end{tabular}

* Final mannose concentration $=0.7 \%(w / v)$. 
Electron microscopy. Organisms grown in tryptone water or harvested from agar were washed twice in sterile distilled water. Because of their potential pathogenicity, cultures of Vibrio cholerae and $V$. eltor were fixed before washing by adding formalin to a final formaldehyde concentration of $0.25 \%(\mathrm{w} / \mathrm{v})$. Comparison of preparations of Vibrio 47I6 fixed with formalin with unfixed preparations indicated that formalin treatment was unlikely to alter the appearance of these organisms. Metal-shadowed preparations were made by placing a loopful of an aqueous suspension of organisms on a formvar-coated copper grid, allowing it to dry in air, and then shadowing with gold-palladium (40:60) at an angle of $20^{\circ}$. Negatively stained preparations were made on carbon-stabilized formvar-coated copper grids. A loopful of an aqueous suspension of organisms was placed on the grid and allowed to dry in air. Then a drop of either aqueous ammonium molybdate ( $\mathrm{I} \% \mathrm{w} / \mathrm{v} ; \mathrm{pH} 7 \cdot 0)$ or potassium phosphotungstate $(\mathrm{I} \%, \mathrm{w} / \mathrm{v} ; \mathrm{pH} 7 \cdot 0)$ was put on the grid and, after I min., the excess removed with filter paper. Preparations were examined in a Siemens Elmiskop I electron microscope using the single condenser, a $200 \mu$ condenser aperture, a $50 \mu$ objective aperture, and an accelerating voltage of $80 \mathrm{kV}$. Micrographs were taken at initial magnifications of 6000-20,000 on Ilford N 50 thin-film half-tone plates. Measurement of the diameters of fimbriae were made from negatives using a plate microscope and a calibrated eyepiece micrometer ('Filar micrometer'; Nikon, Tokyo). Lengths of fimbriae were measured from prints enlarged from the negatives.

\section{RESULTS}

\section{Haemagglutination}

Vibrios examined after 3 serial subcultures at $24 \mathrm{hr}$ in tryptone water incubated at $37^{\circ}$ consistently agglutinated both guinea-pig and human cells (Table 2). These conditions therefore appeared to be suitable and reliable for demonstrating haemagglutination by vibrios. Vibrios grown under other cultural conditions agglutinated these cells less consistently. Of the vibrios, Vibrio eltor gave the strongest haemagglutination reaction. Escherichia coli, Pseudomonas multivorans and Aeromonas liquefaciens when grown in tryptone water or when grown for $72 \mathrm{hr}$ on nutrient agar consistently agglutinated guinea-pig red cells. Haemagglutination by these three organisms was completely inhibited by D-mannose (final conc. $0.7 \%, \mathrm{w} / \mathrm{v}$ ) whereas haemagglutination by the 3 Vibrio strains was only partially inhibited. By partial inhibition we mean that when mannose was included in the mixture which contained organisms and red blood cells, there were fewer, smaller clumps of agglutinated red cells than when no mannose was present.

The 3 Vibrio strains and Aeromonas liquefaciens agglutinated human and guineapig red blood cells equally well. Escherichia coli agglutinated guinea-pig red blood cells strongly and human red blood cells only weakly. Pseudomonas multivorans agglutinated guinea-pig red blood cells but failed to agglutinate human red blood cells.

On no occasion did we obtain haemagglutination with supernatant fluids from cultures or with heated cultures.

\section{Electron microscopy}

The measurements given here are of negatively stained fimbriae except where it is stated that they are of shadowed fimbriae. Thornley \& Horne (I962) reported that the 
$\stackrel{2}{\vdots}$

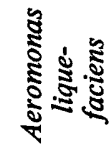

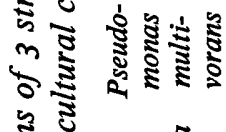

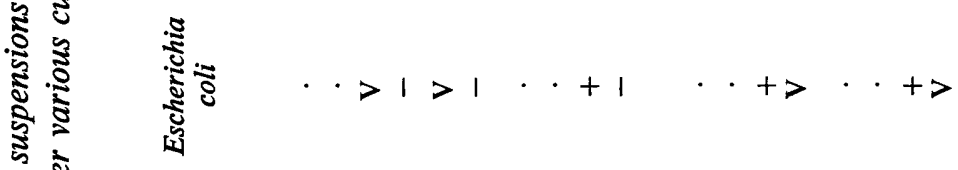

ญे

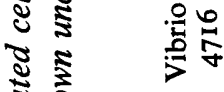

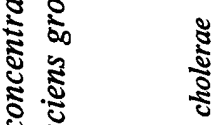

8 :

ป

ริ

8

ㅇำ

ป⿻

.

i

क

ป

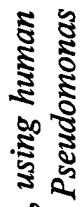

$\frac{1}{2}$

竎方

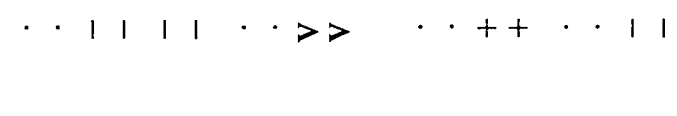

焉

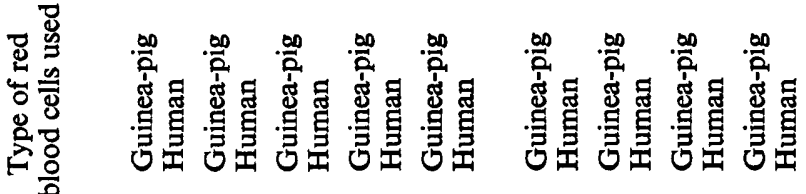

혈

句:

政

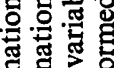

寻

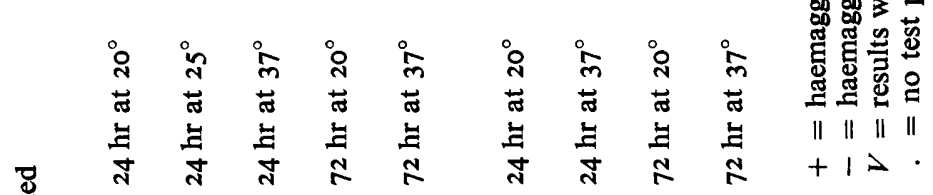

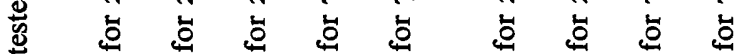

这

.2

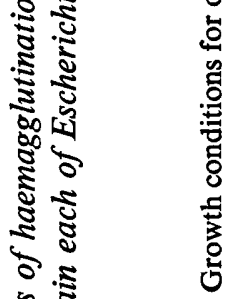

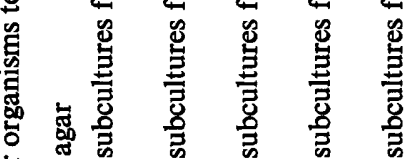

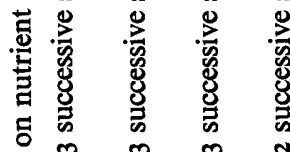

窎 总

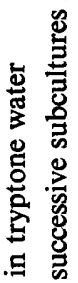

m $m$

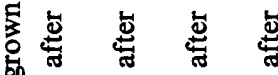

N

两

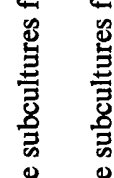

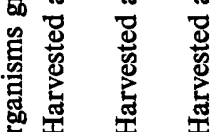

के

\&

4 ถ

ङ

离

趈

总

苞

岁

窎

沗

毒 
diameter of negatively stained fimbriae was approximately $30 \%$ less than that of shadowed fimbriae. The diameters to be expected for negatively stained fimbriae, calculated from micrographs of shadowed fimbriae using this ratio, are given in parentheses in Table 3. It can be seen that our results agree with those of Thornley \& Horne (1962).

Table 3. Measurements of fimbriae found on 3 strains of Vibrio and I strain each of Escherichia coli, Pseudomonas multivorans and Aeromononas liquefaciens

(I) Diameter $(\mathrm{m} \mu)$

Metal-shadowed fimbriae Negatively stained fimbriae

(2) Length $(\mu)$ of longest fimbria seen

\begin{tabular}{|c|c|c|c|c|c|}
\hline $\begin{array}{l}\text { Vibrio } \\
\text { eltor }\end{array}$ & $V$. cholerae & $\begin{array}{l}\text { Vibrio } \\
4716\end{array}$ & $\begin{array}{l}\text { Escheri- } \\
\text { chia } \\
\text { coli }\end{array}$ & $\begin{array}{c}\text { Pseudo- } \\
\text { monas } \\
\text { multi- } \\
\text { vorans }\end{array}$ & $\begin{array}{l}\text { Aeromonas } \\
\text { lique- } \\
\text { faciens }\end{array}$ \\
\hline $\begin{array}{l}11 \cdot 3 \pm 0.7 \\
7 \cdot 9 \pm 0 \cdot 2\end{array}$ & $\begin{array}{l}10.4 \pm 0.5 \\
7.2 \pm 0.3\end{array}$ & $13 \cdot 1 \pm 0.5$ & $\mathrm{II} \cdot \mathrm{I} \pm 0 \cdot 8$ & $\begin{array}{c}8 \cdot 6 \pm 0.3 \\
.\end{array}$ & $\begin{array}{l}9 \cdot 2 \pm 0 \cdot 7 \\
7 \cdot 9 \pm 0 \cdot 3\end{array}$ \\
\hline $\begin{array}{c}(7 \cdot 9) \\
3 \cdot 3\end{array}$ & $\begin{array}{l}(6 \cdot 7) \\
I \cdot 0\end{array}$ & $\begin{array}{l}(9 \cdot 2) \\
I \cdot 8\end{array}$ & $\begin{array}{l}(7 \cdot 7) \\
I \cdot 0\end{array}$ & $(6 \cdot 0)$ & $(6 \cdot 4)$ \\
\hline $3 \cdot 3$ & $I \cdot 0$ & $\mathrm{I} \cdot 8$ & $I \cdot O$ & $1 \cdot 5$ & $\mathbf{I} \cdot 3$ \\
\hline
\end{tabular}

Figures in parentheses are the estimated values of diameters of negatively stained fimbriae assuming that these values are $30 \%$ less than those of shadowed fimbriae (Thornley \& Horne, 1962).

Values for measured diameters of fimbriae (between 7 and 40 diameters measured for each value) are given as the mean \pm the standard deviation.

When determining lengths of fimbriae we measured only those fimbriae which appeared to be clearly attached to the organisms and which were not close to fimbriae from other organisms.

Vibrio eltor. About $50 \%$ of the organisms examined had long, curved fimbriae. These fimbriae did not branch or taper; the average diam. was $7.9 \mathrm{~m} \mu$, and the maximum length was more than $2.5 \mu$. The number of fimbriae per organism and the length increased with the number of subcultures in tryptone water and decreased with the number of subcultures on nutrient agar. The maximum number of fimbriae per organism was 50 (Pl. I, fig. I; Pl. 2, fig. 2, 3).

Vibrio cholerae. Unbranched fimbriae which did not taper were found on about I0 \% of the organisms. The fimbriae were short and curved and had an average diameter of $7.2 \mathrm{~m} \mu$. The maximum length was $\mathrm{I} \cdot 0 \mu$ and there were up to 9 fimbriae per organism. (Pl. 3, fig. 4).

Vibrio 4716 . About 10 \% of the organisms examined after 3 serial subcultures at $24 \mathrm{hr}$ intervals in tryptone water had I, 2 or 3 fimbriae. Measured from shadowed preparations the fimbriae had an average diameter of I3. I $\mathrm{m} \mu$ and a maximum length of $\mathrm{r} \cdot 8 \mu$ (Pl. 3, fig. 5). The fimbriae were not branched and did not taper. However, organisms examined after I subculture or 2,3 or 6 serial subcultures at $24 \mathrm{hr}$ intervals on nutrient agar were surrounded by a mass of branching strands (Pl. 4, fig. 6, 7). These strands increased in quantity as the number of subcultures increased, they tapered at the distal end and they branched. The average diameter of the narrowest strands was $6.8 \mathrm{~m} \mu$, which is less than that of the fimbriae seen on organisms after one $24 \mathrm{hr}$ subculture in tryptone water from stock. Furthermore, bearing in mind that shadowed fimbriae appear to be $30 \%$ wider than do negatively stained fimbriae, there was a discrepancy between the values for the diameter of the strands seen in negatively stained preparations $(6.8 \mathrm{~m} \mu)$ and in metal-shadowed preparations $(5.7 \mathrm{~m} \mu)$. The discrepancy could be explained by assuming that the strands were flat, not round like fimbriae 
(Brinton, 1965), so that they cast very little shadow.We concluded that the branching strands were unlikely to be fimbriae but were possibly formed in a random way from some material such as slime. These strands would have obscured any fimbriae that were present.

Escherichia coli. About 10\% of the organisms from cultures grown either on solid or in liquid media had numerous short, straight fimbriae which did not branch or taper. The average diameter was $\mathrm{II} \cdot \mathrm{I} \mathrm{m} \mu$ (in shadowed preparations) and the maximum length was $\mathrm{I} \cdot 0 \mu$. (PI. 5, fig. 8).

Pseudomonas multivorans. About $10 \%$ of the organisms from cultures grown either on solid or in liquid media had numerous, short, straight fimbriae which did not branch or taper. The average diameter was $8.6 \mathrm{~m} \mu$ (in shadowed preparations) and the maximum length was $\mathrm{I} \cdot 5 \mu$. (Pl. 5, fig. 9).

Aeromonas liquefaciens. About $10 \%$ of the organisms from cultures grown either on solid or in liquid media had numerous short, straight fimbriae which did not branch or taper. The average diameter was $7 \cdot 9 \mathrm{~m} \mu$ and the maximum length was $I^{\circ} 3 \mu$. (Pl. 6, fig. 10, I I).

\section{DISCUSSION}

Vibrios show a type of haemagglutination which in some ways resembles haemagglutination by fimbriated enterobacteria. Supernatant fluid from tryptone water cultures does not agglutinate red blood cells, thus indicating that the haemagglutinating agent is bound to the organism.Heat-treated organisms also do not haemagglutinate. Haemagglutination by the vibrios differs from haemagglutination by fimbriated enterobacteria in being partially inhibited by mannose: haemagglutination by enterobacteria is either completely inhibited or else is completely unaffected (Shedden, 1962). Similar results to ours were obtained by Barua \& Mukherjee (I965) working with strains of Vibrio eltor and $V$. cholerae.

Haemagglutination by various enterobacteria usually indicates that these organisms possess fimbriae but haemagglutination can occur without fimbriae being involved (non-fimbrial haemagglutination). Non-fimbrial haemagglutination encountered by Duguid et al. (1955, 1966) during studies of various enterobacteria had some distinctive features. These features (the range of species of red cells agglutinated, elution from red cells at high temperature, agglutination not inhibited by mannose) enabled fimbrial and non-fimbrial haemagglutination to be differentiated from one another. It is difficult to know how justifiable it is to apply the information on haemagglutination by enterobacteria to the interpretation of haemagglutination by vibrios. However, we consider that the following points, taken together, indicate that the vibrios we examined are capable of producing fimbriae and that these fimbriae are probably responsible for haemagglutination.

(I) We did not detect elution from red cells when the temperature rose during the tile test or in some other tests we performed in tubes. Observations on elution were complicated by the haemolysis of agglutinated red cells as the temperature was raised to $50^{\circ}$. Doorenbos (1932; cited by Pollitzer, 1959) observed that haemagglutination by el tor vibrios was as good at $37^{\circ}$ as at $0^{\circ}$, while Barua \& Mukherjee (1965) found that these organisms did not haemagglutinate at $4^{\circ}$ but did do so at $30^{\circ}$ and $37^{\circ}$. It appears that haemagglutination by vibrios is, with respect to temperature, similar to fimbrial haemagglutination by Escherichia coli (Duguid, 1964) and by various Salmonella species (Duguid et al. I966). 
(2) Haemagglutination by vibrios was partially inhibited by mannose. Mannose inhibition of non-fimbrial haemagglutination by bacteria has not been reported but haemagglutination due to fimbriae is often mannose sensitive.

(3) The strongest and most reliable haemagglutination by Vibrio eltor occurred when organisms were grown under conditions which gave most fimbriae as judged by electron microscopy.

We found, as did Barua \& Chatterjee (I964), that the haemagglutination reaction of vibrios was much weaker than was that of Escherichia coli in the fimbriate phase. The haemagglutinating activity of enterobacteria varies directly with the degree of fimbriation (Duguid \& Gillies, 1957). Barua \& Chatterjee (1964) assumed that the same relationship might hold with vibrios and suggested that a smaller percentage of el tor vibrios than of $E$. coli organisms in the fimbriate phase possess fimbriae. In our electron microscope study we obtained some evidence to support the suggestion that the intensity of haemagglutination is related to the percentage of fimbriate organisms and to the number of fimbriae on organisms. Only about $10 \%$ of our Vibrio cholerae organisms had fimbriae and the maximum number seen per organism was 9. This strain gave weaker haemagglutination reactions than did $V$. eltor, which had up to 50 fimbriae per organism and which had fimbriae on about $50 \%$ of organisms. It might have been possible for us to obtain a stronger haemagglutination reaction by altering cultural conditions (Bales \& Lankford, 196I) or by using a denser bacterial suspension in the test (Finkelstein \& Mukerjee, 1963; Barua \& Mukherjee, 1965) but we did not make an intensive study of these factors.

Barua \& Chatterjee (1964) made an electron microscope examination of el tor vibrios and observed fimbriae with diameters ranging from 6 to $8 \mathrm{~m} \mu$. There were a small number of fimbriae per organism and Barua \& Chatterjee had some difficulty in detecting them because there was a slime layer surrounding the organisms. This difficulty led Barua \& Mukherjee (1965) to conclude that fimbriae had not been convincingly demonstrated in these vibrios. In our work the morphology and the estimated diameters of the fimbriae were similar to those reported by Barua $\&$ Chatterjee (1964). There was no slime layer around the cell walls of $V$. cholerae or $V$. eltor but Vibrio 47I6, under certain conditions, was surrounded by structures which may represent slime. These structures appear to be distinct from fimbriae but may obscure fimbriae which may be present on the organisms.

The vibrio fimbriae do not appear to correspond to any of the 6 types of fimbriae (designated I-V and F) described by Brinton (1965) or of the 7 types (designated I-6 and F) described by Duguid et al. (1966). The general dimensions are similar to those of types I, IV and F fimbriae of Brinton and to those of types I, 2 and F of Duguid et al. However the vibrio fimbriae are distinct from type IV of Brinton because they do not have a helical structure and from type 2 of Duguid because they are apparently associated with haemagglutinating activity. In the following discussion the term 'type I fimbriae' used without qualification means type I fimbriae of Duguid et al. (I966) and type I fimbriae of Brinton (1965). We compared our electron micrographs of vibrio fimbriae with electron micrographs of type I fimbriae (e.g. Brinton, I965; Duguid et al. I966) and of F fimbriae (Brinton, I965; Lawn 1966). From this it appeared that: (I) type I fimbriae are straighter and more numerous per organism than are vibrio fimbriae; (2) F fimbriae are present in smaller numbers per organism, at least than is the case with fimbriae on Vibrio eltor, and are generally longer than are 
vibrio fimbriae. It may be that the filaments on the surface of vibrios are filamentous phages. We think that this is unlikely but are unable to comment critically on the possibility at present, especially as it is conceivable that there is an evolutionary relationship between certain fimbriae and filamentous phages (Bradley, 1966).

Brinton (1965) demonstrated that the presence of F fimbriae of Escherichia coli is correlated with the presence of the $\mathrm{F}$ factor, which confers fertility. Fertility has been demonstrated in vibrios by Bhaskaran (1960) and this makes us wonder if the fimbriae of vibrios are associated with transfer of genetic material in addition to being associated with haemagglutination. So far as we know, the haemagglutinating properties of $\mathrm{F}$ fimbriae on $E$. coli and the fimbriation of fertile $V$. cholerae have not yet been determined.

In order to have some known fimbriate organisms for comparison in this study we included a strain of Escherichia coli, which gave mannose-sensitive haemagglutination, and two strains of polarly-flagellated organisms, Pseudomonas multivorans and Aeromonas liquefaciens, previously shown by one of us (W.H.) to possess fimbriae. We found that in their dimensions, morphology and typical number per organism, the fimbriae on these three strains corresponded to type I fimbriae. Haemagglutination occurred with all three strains but $A$. liquefaciens and $P$. multivorans showed a minor difference from the haemagglutination chracteristics of type I fimbriae (Duguid et al. 1966). Aeromonas liquefaciens agglutinated human and guinea-pig red cells equally well, while $P$. multivorans agglutinated guinea-pig red cells but failed to agglutinate human red cells. Type I fimbriae agglutinate guinea-pig red cells well but only agglutinate human red cells weakly (Duguid, 1964; Duguid et al. 1966). So far as we are aware this is the first published report of type I fimbriae on A. liquefaciens and $P$. multivorans. It has been the experience of one of us (W.H.) during electron microscopy of polarly flagellated organisms that fimbriae are possessed by only a very few species.

We would like to thank Professor J. P. Duguid for his helpful suggestions in the interpretation of the electron micrographs and Dr J. M. Shewan for his interest in this work.

A grant from the Ministry of Technology enabled one of us (J.M.T.) to perform part of this work at Torry Research Station. The electron microscopy described in this paper was carried out as part of the programme of the Ministry of Technology.

\section{REFERENCES}

Bales, G. L. \& Lankford, C. E. (1961). An adherance factor of Vibrio cholerae. Bact. Proc. p. I I8. BARUA, D. \& ChatterJee, S. N. (1964). Electron microscopy of El Tor vibrios. Indian J. med. Res. 52, 828.

BARUA, D. \& MukHERJEe, A. C. (1965). Haemagglutinating activity of El Tor vibrios and its nature. Indian J. med. Res. 53, 399.

Bhaskaran, K. (I960). Recombination of characters between mutant stocks of Vibrio cholerae, strain I62. J. gen. Microbiol. 23, 47.

Bradley, D. E. (1966). The structure and infective process of a Pseudomonas aeruginosa bacteriophage containing ribonucleic acid. J. gen. Microbiol. 45, 83 .

BRINTON, C. C. (1959). Non-flagellar appendages of bacteria. Nature, Lond. 183, 782.

Brinton, C. C. (1965). The structure, function, synthesis and genetic control of bacterial pili and a molecular model for DNA and RNA transport in Gram negative bacteria. Trans. N.Y. Acad. Sci. 27, 1003. 
Journal of General Microbiology, Vol. 5I, No. 2

Plate I

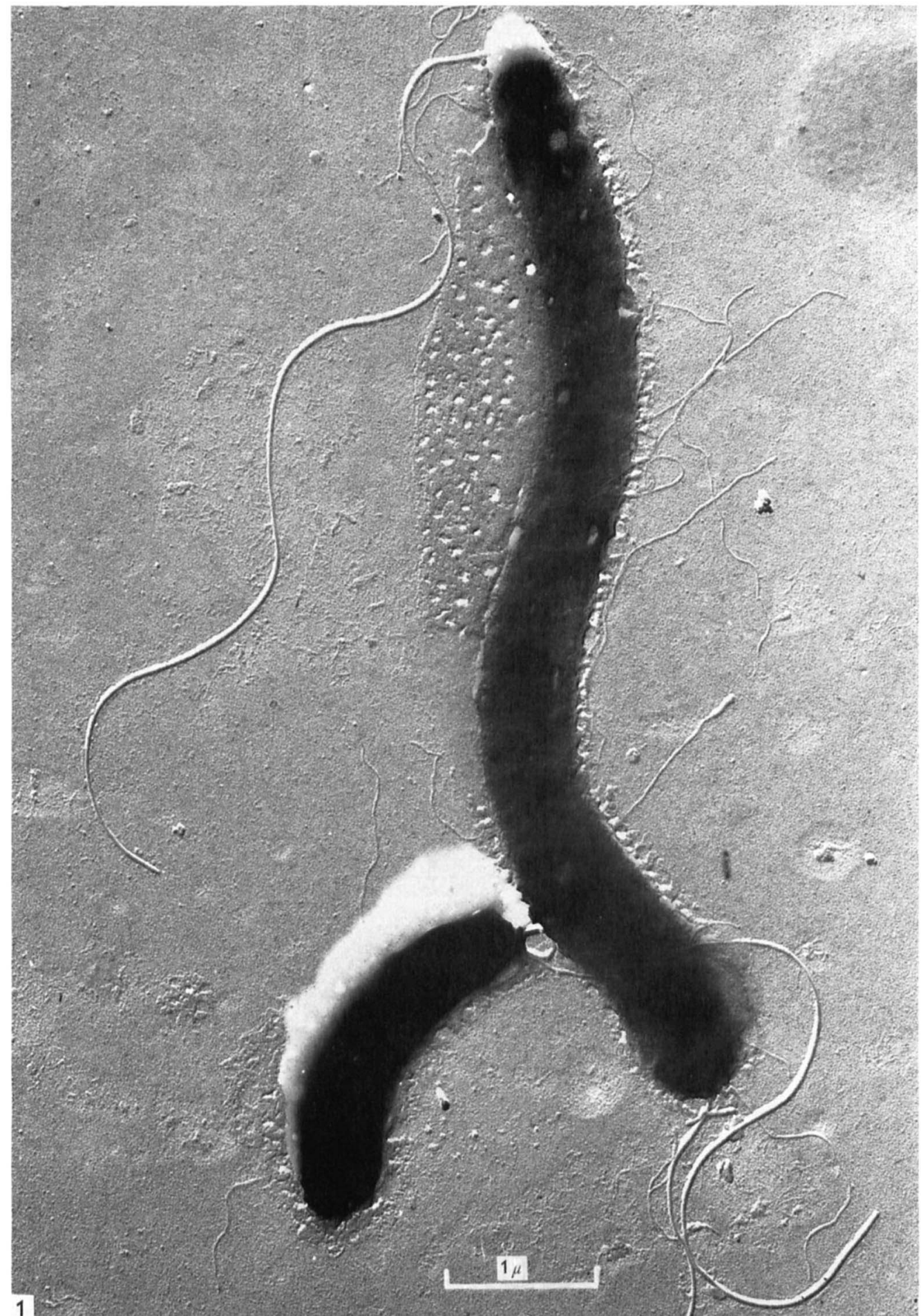


Journal of General Microbiology, Vol. 5I, No. 2

Plate 2
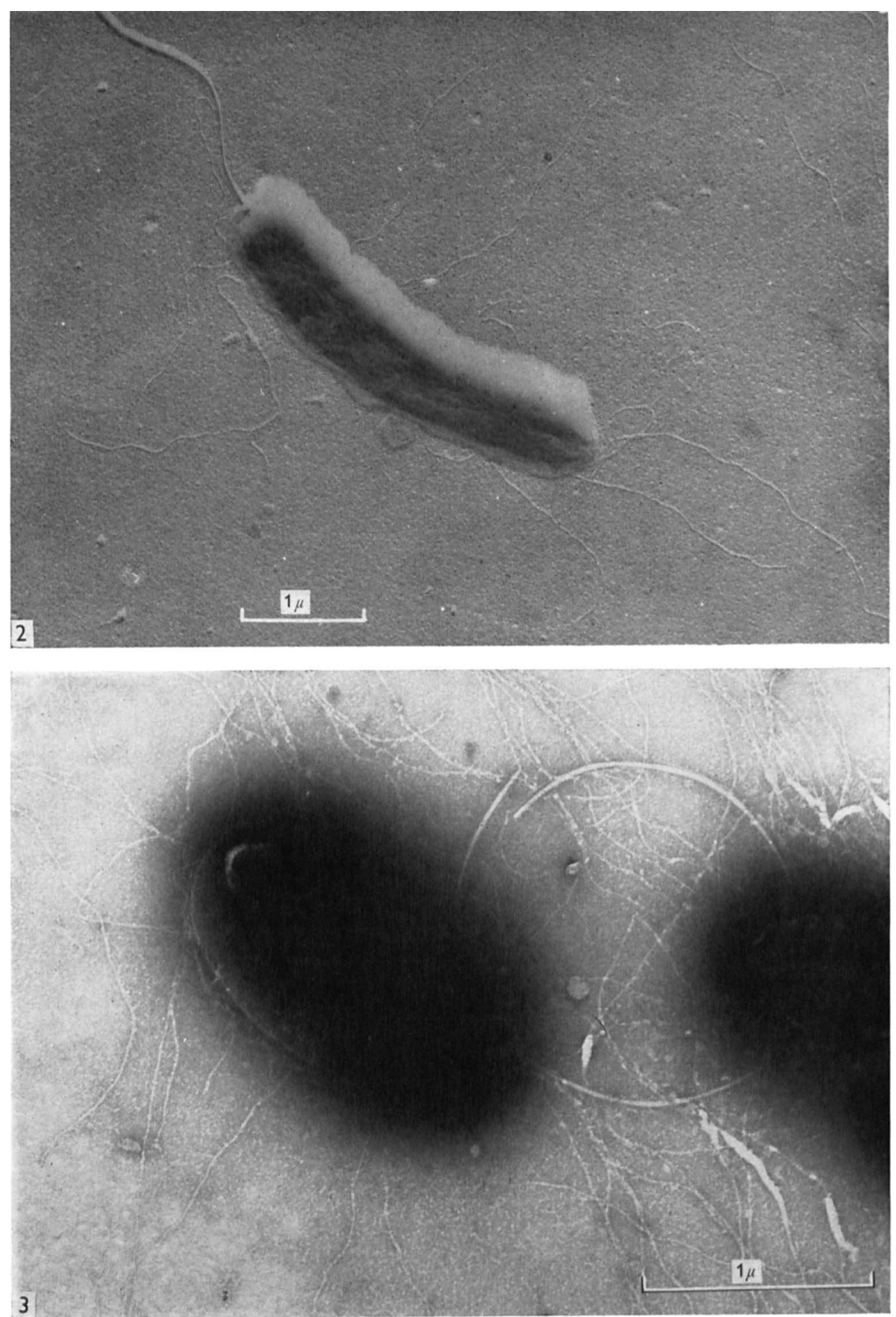

J. M. TWEEDY, R. W. A. PARK AND W. HODGKISS 

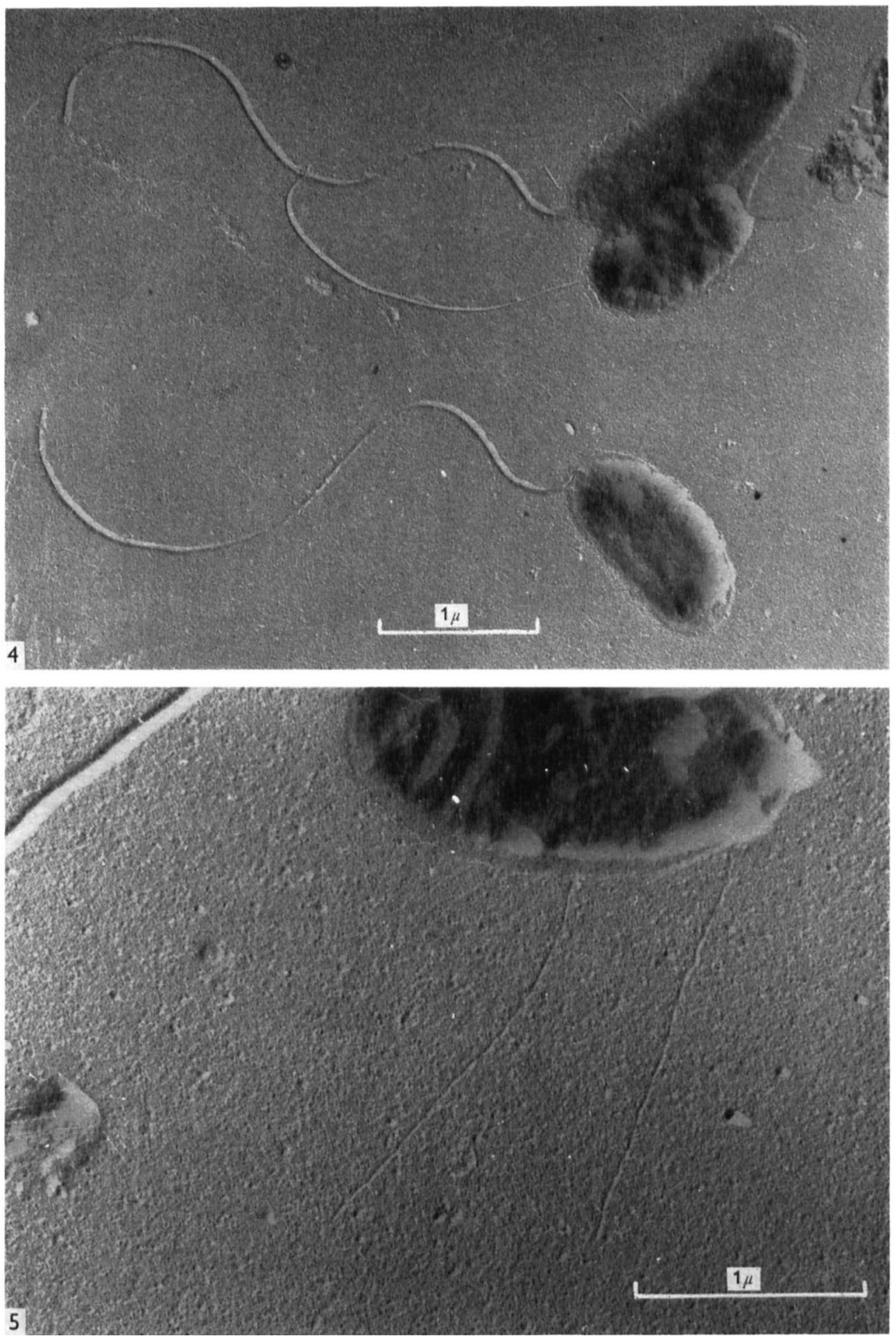

J. M. TWEEDY, R. W. A. PARK AND W. HODGKISS 

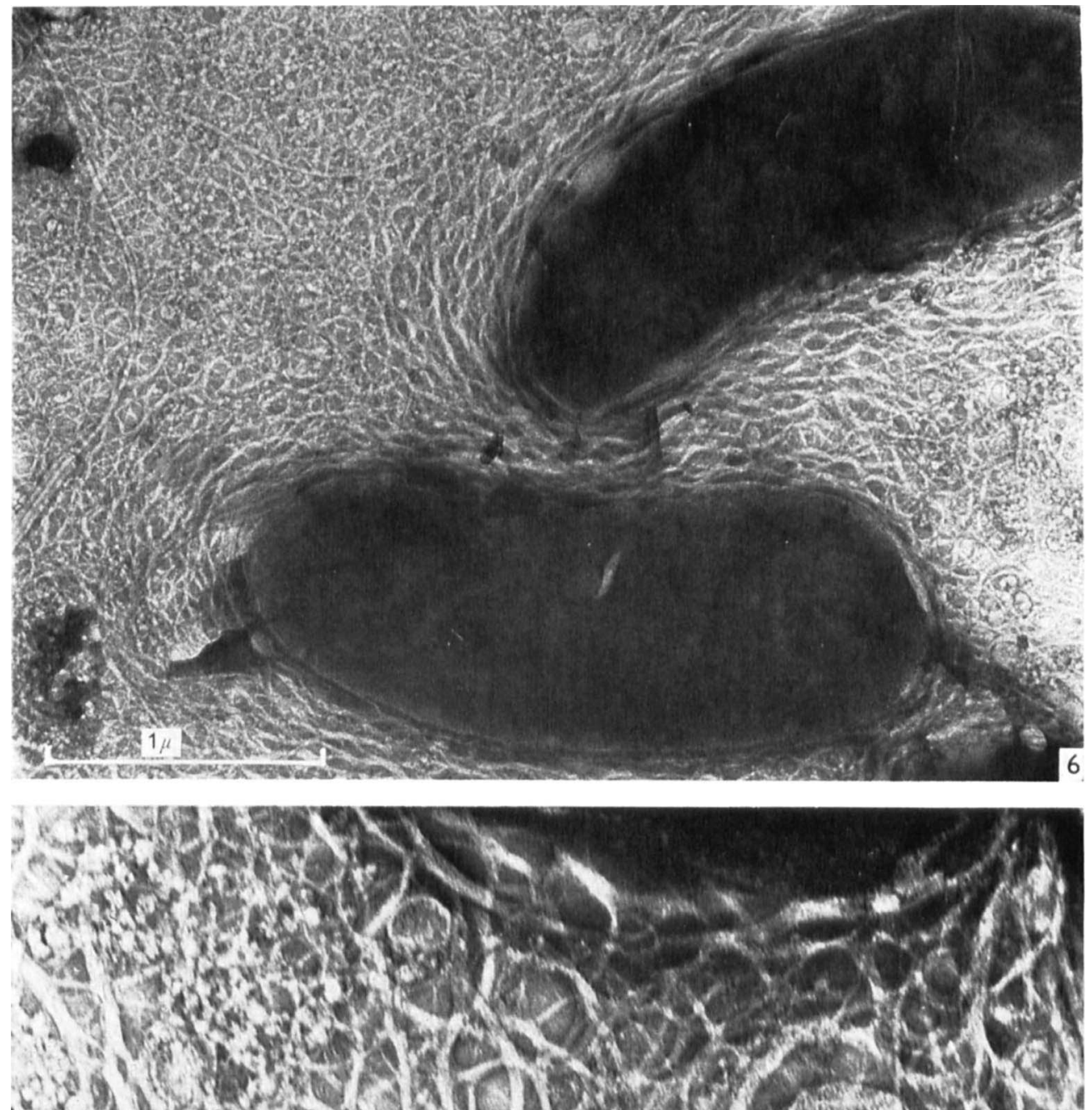

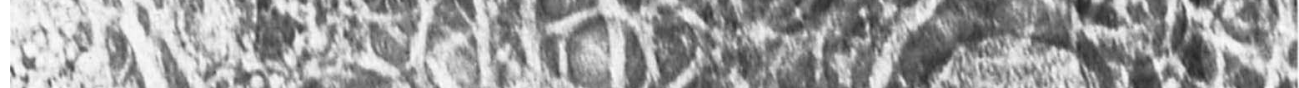
int a

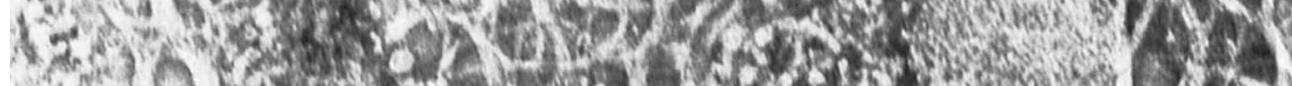

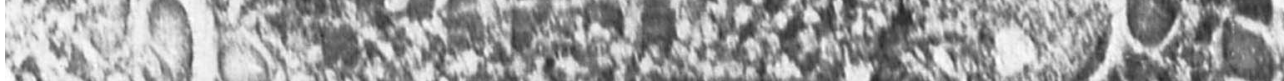

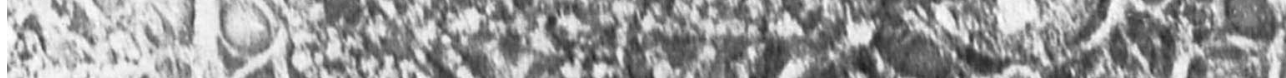

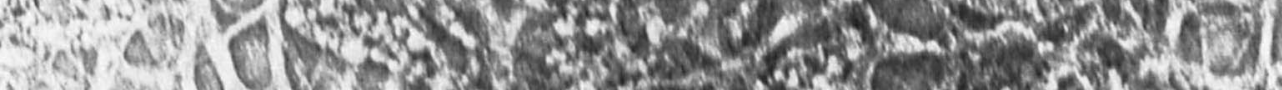

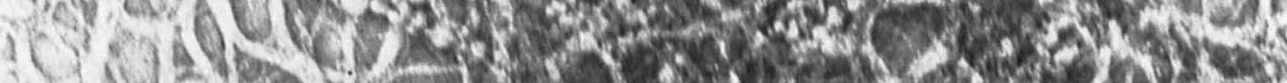

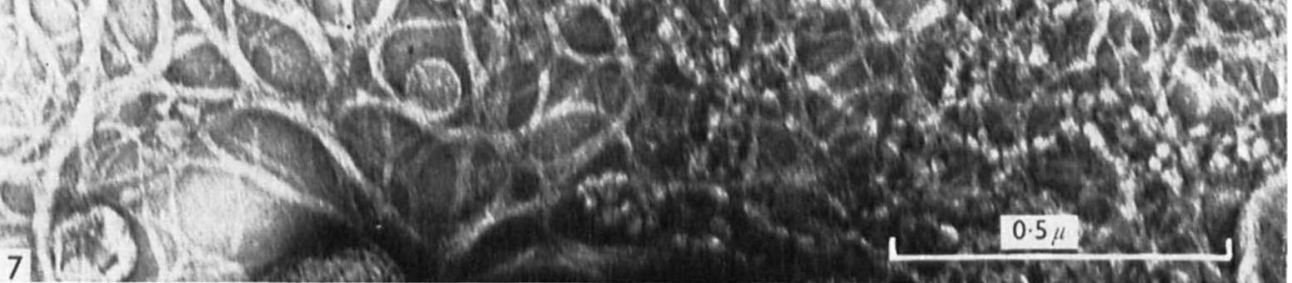

J. M. TWEEDY, R. W. A. PARK AND W. HODGKISS 

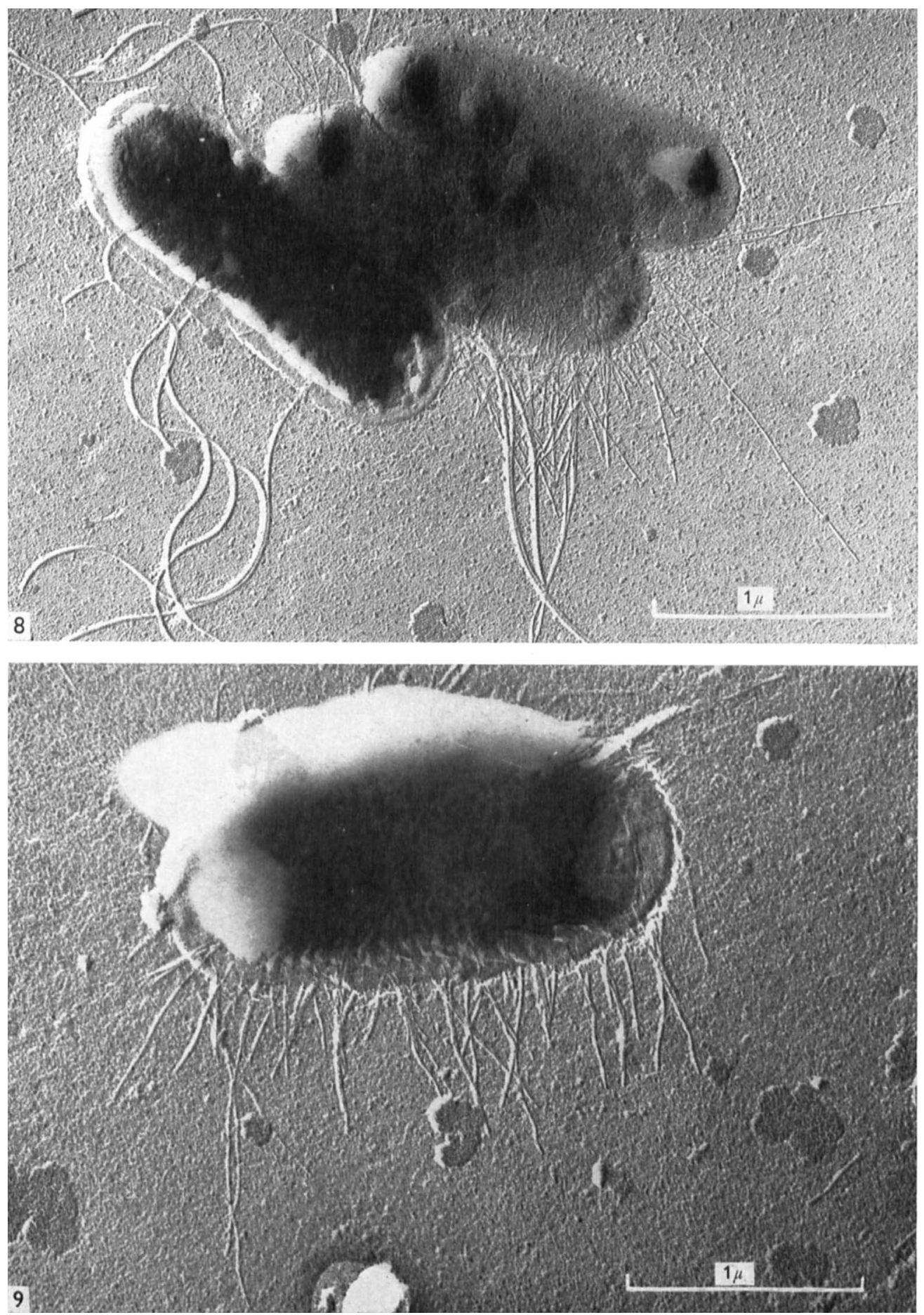

J. M. TWEEDY, R. W. A. PARK AND W. HODGKISS 

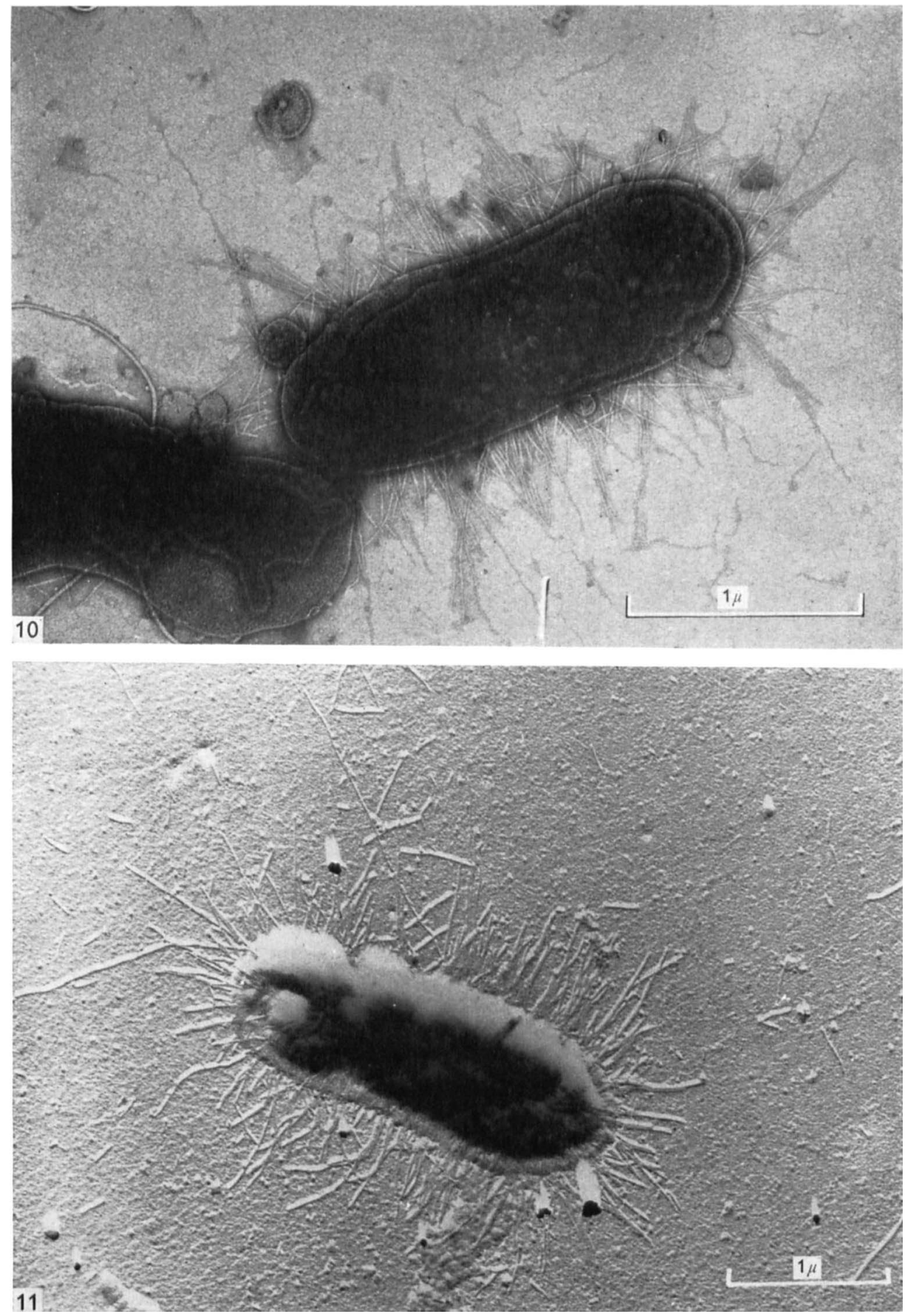

J. M. TWEEDY, R. W. A. PARK AND W. HODGKISS 
CRUickshank, R. (1965). Medical Microbiology, i Ith ed. London: Livingstone.

DuguID, J. P. (1959). Fimbriae and adhesive properties in Klebsiella strains. J. gen. Microbiol. 2r, 27.

Duguid, J. P. (1964). Functional anatomy of Escherichia coli with special reference to enteropathogenic E. coli. Rev. lat-amer. Microbiol. 7, Suppls. 13-I4.

Duguid, J. P. (1966). Note on the terms 'fimbriae' and 'pili'. J. Path. Bact. 92, 137.

Duguid, J. P. \& Gillies, R. R. (1957). Fimbriae and adhesive properties in dysentery bacilli. J. Path. Bact. 74, 397.

Duguid, J. P., Anderson, E. S. \& CAmpbell, I. (1966). Fimbriae and adhesive properties in Salmonellae. J. Path. Bact. 92, 107.

Duguid, J. P., Smith, I. W., Dempster, G. \& Edmunds, P. N. (I955). Non-flagellar filamentous appendages ('fimbriae') and haemagglutinating activity in Bacterium coli. J. Path. Bact. 7o, 335.

FinkelsteIn, R. A. \& MukerJeE, S. (1963). Haemagglutination: a rapid method for differentiating Vibrio cholerae and El Tor vibrios. Proc. Soc. exp. Biol. Med. I12, 355.

LAwN, A. M. (1966). Morphological features of the pili associated with Escherichia coli $\mathrm{K}$ I 2 carrying $\mathrm{R}$ factors or the $\mathrm{F}$ factor. J. gen. Microbiol. 45, 377.

Miles, E. M. \& Miles, A. A. (1951). The identity of Proteus hydrophilus Bergey et al. and Proteus melanovogenes Miles \& Halnan, and their relation to the genus Aeromonas Kluyver \& Van Niel. J. gen. Microbiol. 5, 298.

Pollitzer, R. (1959). Cholera. W. H. O. Monogr. Ser. no. 43.

SHEDDEN, W. I. H. (1962). Fimbriae and haemagglutinating activity in strains of Proteus hauseri. J. gen. Microbiol. 28, I.

Stanier, R. Y., Palleroni, N. J. \& Doudoroff, M. (I966).The aerobic pseudomonads: a taxonomic study. J. gen. Microbiol. 43, I59.

THORNLEY, M. J. \& HORNE, R. W. (I962). Electron microscope observations on the structure of fimbriae, with particular reference to Klebsiella strains, by the use of the negative staining technique. J. gen. Microbiol. 28, 51 .

\section{EXPLANATION OF PLATES}

All the figures are electron micrographs of organisms. Shadowed preparations were made of organisms mounted on formvar films using gold-palladium $(40: 60)$ at $20^{\circ}$; negatively stained preparations were made of organisms mounted on carbon-stabilized formvar films using ammonium molybdate.

\section{Plate I}

Fig. I. Vibrio eltor NCTC 5395 after 3 serial subcultures at $24-\mathrm{hr}$ intervals in tryptone water incubated at $37^{\circ}$. The organisms bear long fimbriae which, unlike common (type I) fimbriae of enterobacteria, are not straight. Formalin fixed, shadowed.

\section{Plate 2}

Fig. 2. V. eltor NCTC 5395 after 3 serial subcultures at 24 -hr intervals in tryptone water incubated at $37^{\circ}$. Several long fimbriae are visible. Formalin fixed, shadowed.

Fig. 3. V. eltor NCTC 5395 after 2 serial subcultures at 72 -hr intervals in tryptone water incubated at $37^{\circ}$. Both organisms have numerous fimbriae. Formalin fixed, negative stain.

\section{Plate 3}

Fig. 4. V. cholerae NCTC $802 \mathrm{I}$ after 3 serial subcultures at 24-hr intervals in tryptone water incubated at $37^{\circ}$. One organism bears a few short fimbriae. Formalin-fixed, shadowed.

Fig. 5. Vibrio 4716 after 3 serial subcultures at 24 -hr intervals in tryptone water incubated at $37^{\circ}$. Two fimbriae are visible. Unfixed, shadowed.

\section{Plate 4}

Fig. 6. Vibrio 4716 after 6 serial subcultures at 24 -hr intervals on nutrient agar incubated at $37^{\circ}$. A dense network of strands is present and no fimbriae can be seen. Note the sheathed flagellum. Unfixed, negative stain. 
Fig. 7. Vibrio 4716 after growth for $24 \mathrm{hr}$ on nutrient agar inoculated from a stock culture. Any fimbriae which may be present cannot be detected because of the dense network of branched strands. Unfixed, negative stain.

\section{Plate 5}

Fig. 8. Escherichia coli after 6 serial subcultures at 24 -hr intervals on nutrient agar incubated at $37^{\circ}$. There are numerous straight fimbriae on one of the organisms. Unfixed, shadowed.

Fig. 9. Pseudomonas multivorans NCIB 969I after 3 serial subcultures at 24 -hr intervals in tryptone water incubated at $20^{\circ}$. The organism bears numerous straight fimbriae. Unfixed, shadowed.

\section{Plate 6}

Fig. 10. Aeromonas liquefaciens NCMB 87 after 3 serial subcultures at 24 -hr intervals in tryptone water incubated at $20^{\circ}$. One organism bears numerous straight fimbriae. Unfixed, negative stain.

Fig. I1. A. liquefaciens NCMB 87 after 3 serial subcultures at $24-\mathrm{hr}$ intervals in tryptone water incubated at $20^{\circ}$. The organism bears numerous straight fimbriae. Unfixed, shadowed. 